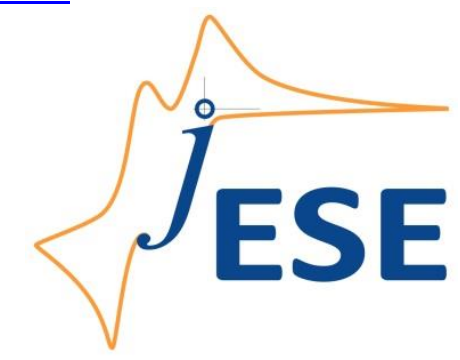

Open Access : : ISSN 1847-9286

www.jESE-online.org

Original scientific paper

\title{
Three-dimensional mathematical model to study effects of geometrical parameters on performance of solid oxide fuel cell
}

\author{
Vikalp Jha, Vikranth Kumar Surasani and Balaji Krishnamurthy ${ }^{\bowtie}$ \\ Department of Chemical Engineering, BITS Pilani, Hyderabad 500078, India \\ Corresponding author: ${ }^{\square}$ balaji.krishb1@gmail.com
}

Received: August 31, 2021; Accepted: September 12, 2021; Published: September 25, 2021

\begin{abstract}
A 3D mathematical model is developed to study effects of various geometrical parameters such as cathode to anode thickness ratio, rib width, and channel width under various flow conditions, on the performance of solid oxide fuel cell (SOFC). These parameters represent the cathode supported configuration of the solid oxide fuel cell. It is observed from simulation results that performance of SOFC fuel cell is increased at higher cathode to anode thickness. Simulation results also showed that for different volumetric flow rates, the current density and fuel cell performance decrease as rib width increases, what is due to higher contact resistance. It is also shown that by increasing the channel width, the fuel cell performance was increased due to increase in the reaction surface area. Simulation results are compared and validated with literature experimental data, showing well agreement.
\end{abstract}

\section{Keywords}

current density; channel width; cathode; cathode to anode thickness.

\section{Introduction}

In past several years, solid oxide fuel cells (SOFCs) of planar configurations were established as some of the most efficient energy conversion devices, convenient for various industrial applications. Various researchers have worked on different configurations (tubular, planar, ...) of solid oxide fuel cells serving for conversion of chemical energy to electrical energy. Yakabe et al. [1] studied a 3-dimensional mathematical model of a planar SOFC to observe the effect of heat transfer and chemical reactions in fuel cells of co-flow parallel and counter flow configurations. The authors postulated that co-flow configurations are better in comparison to counter flow configuration of planar SOFC owing to lower internal stresses. Sun et al. [2] studied the experimental fabrication of anode supported single chamber SOFC for various electrolyte and cathode structures. The authors postulated that the fuel cell performance is better for lower electrolyte thickness and with increment in fuel (methane and hydrogen) and oxidizer ratio. 
Chinda [3] studied a micro scale model of SOFC in order to study its performance. The author postulated that an increase of the electrode surface area improves the performance of the fuel cell. Shichuan et al. [4] studied a 3D numerical model of anode and cathode supported SOFC stack to observe effects of cell design on the fuel cell stack performance. The authors postulated that for the optimal rib width, cathode supported fuel cell is more efficient in comparison to anode supported fuel cell. Zaccaria et al. [5,6] studied a 1D transient model to simulate a co-flow parallel anode supported SOFC to study the effect of model characteristics on fuel cell degradation. The authors postulated that the current density, fuel utilization and temperature at inlet are reduced with time, whereas at cell outlet these parameters increase with time. These authors also studied the fuel cell performance for ohmic, activation and diffusion losses on degradation of SOFC. Cunio et al. [7] developed a fuel cell degradation model for SOFC and a gas turbine hybrid system. The authors postulated that the fuel cell life was increased for hybrid systems in comparison to stand alone configurations. Giosue et al. [8] developed a computational fluid dynamics model to analyse the thermal effect, and flow rate of a SOFC system in the fuselage of a hybrid electric mini unmanned aerial vehicle. Khan et al. $[9,10]$ studied experimentally the effect of applied current density on anode supported tubular SOFC. The authors postulated that with increasing time, cell voltage and power density decrease at higher current densities, whereas degradation rate increases with time.

Shen et al. [11] developed a 3D mathematical model to analyse fuel cell performance in channel flow with consideration on obstacles to see thermal and chemical reaction effect on SOFC. The authors postulated that the peak temperature of fuel cell with obstacles is lower than fuel cell without obstacles, and maximum current density is observed at the cathode of fuel cell. Bianco et al. [12] studied transient degradation of material in the interconnect between anode and cathode in SOFC. Dwivedi [13] studied the effect of various materials used for anodes, cathodes and electrolytes of SOFC. The author postulated that among various materials used for efficient electrolytes, Yttriastabilized zirconia (YSZ) is the most efficient. Zhou at al. [14] studied the effect of diffusion of CO and $\mathrm{CO}_{2}$ between the electrodes in a direct carbon solid oxide fuel cell. The authors postulated that the fuel cell performance decreases with increase of a distance between electrodes.

Min et al. [15] developed a 1D model for thermodynamic analysis of SOFC stack and its operating conditions. The authors postulated that an increase in current density is suitable for more power density and thermal energy utilization. Wang et al. [16] studied a 3D finite element-based model to study effect of inhomogeneous oxidation on mechanical degradation of anode supported SOFC where inhomogeneous oxidation induces a large stress gradient in anode. Hussain et al. [17] studied various electrochemical properties in a 3-dimensional model of SOFC. The authors showed that with an increase of cell temperature, the overall performance of SOFC increases due to enhanced electrochemical reaction rate and lower concentration loss. The authors also stated that with reduced anode thickness and electrolyte thickness, the fuel cell performance increases as result of reduced ohmic loss and concentration loss, respectively.

In this study, a 3-dimensional mathematical model is developed to study the effect of various geometrical parameters such as cathode to anode thickness ratio, and the effect of flow conditions at different rib to channel width ratios on the performance of solid oxide fuel cell (SOFC). To the best of our knowledge, these have never been studied before.

\section{Model development}

\section{Model assumptions}

a) All fuel cell reactions are considered under steady state. 
b) Laminar flow is considered (Reynolds number $=25$, based on channel dimensions).

c) Water formation is assumed in vapour form under high operating temperature.

d) All reacted vapour and gases are considered as ideal gases.

\section{Governing equations}

At anode:

$\mathrm{H}_{2}+\mathrm{O}^{2-} \rightarrow \mathrm{H}_{2} \mathrm{O}+2 \mathrm{e}^{-}$

At cathode:

$0.5 \mathrm{O}_{2}+2 \mathrm{e}^{-} \rightarrow \mathrm{O}^{2-}$

In the channels, gas flow is governed by the Navier-Stokes equations. The mass conservation equation is given by:

For anode:

$\nabla\left(\rho \vec{u}_{\mathrm{a}}\right)=0$

For cathode:

$\nabla\left(\rho \vec{u}_{c}\right)=0$

\section{Momentum equation}

For anode (channel flow):

$$
\begin{aligned}
& \rho \vec{u}_{\mathrm{a}} \vec{u}_{\mathrm{a}}=-\nabla\left(-p \mathrm{I}_{\mathrm{i}, \mathrm{j}}+\tau_{\mathrm{i}, \mathrm{j}}\right) \\
& \left.\tau_{\mathrm{i}, \mathrm{j}}=\mu\left[\nabla \vec{u}_{\mathrm{a}}+\left(\nabla \vec{u}_{\mathrm{a}}\right)^{T}\right]-\frac{2}{3} \mu\left(\nabla \vec{u}_{\mathrm{a}}\right)\right)_{\mathrm{i}, \mathrm{j}}
\end{aligned}
$$

For cathode (channel flow):

$$
\begin{aligned}
& \rho \vec{u}_{\mathrm{c}} \vec{u}_{\mathrm{c}}=-\nabla\left(-p l_{\mathrm{i}, \mathrm{j}}+\tau_{\mathrm{i}, \mathrm{j}}\right) \\
& \left.\tau_{\mathrm{i}, \mathrm{j}}=\mu\left[\nabla \vec{u}_{\mathrm{c}}+\left(\nabla \vec{u}_{\mathrm{c}}\right)^{T}\right]-\frac{2}{3} \mu\left(\nabla \vec{u}_{\mathrm{c}}\right)\right)_{\mathrm{i}, \mathrm{j}}
\end{aligned}
$$

In eqns. (3-8), $\rho$ is the density, $u_{\mathrm{a}}$ and $u_{\mathrm{c}}$ is the inlet velocity vector at anode and cathode, $p$ is the pressure, $\tau_{\mathrm{i}, \mathrm{j}}$ is the viscous stress tensor, $l_{\mathrm{i}, \mathrm{j}}$ is identity tensor and $\mu$ is the dynamic viscosity.

\section{Secondary current distribution}

The electrochemical reactions at the electrodes, and their kinetics responsible for activation over-potential are described by Butler-Volmer equation $[17,18]$.

$$
i=i_{0}\left[\exp \left(\frac{-\alpha_{\mathrm{R}} F}{R T} \eta\right)-\exp \left(\frac{-\alpha_{0} F}{R T} \eta\right)\right]
$$

where $i$ is the current density, $i_{0}$ is the exchange current density, and $\alpha_{\mathrm{R}}$ and $\alpha_{0}$ are transfer coefficients, $T$ is the operating temperature, $F$ and $R$ are the Faraday and the gas constants, and $\eta$ is the overpotential.

When the overpotential is high as for the cathode, Butler-Volmer equation can be simplified to the Tafel equation $[17,18]$

$$
\eta=A \ln \left(\frac{i}{i_{0}}\right)
$$

where $A$ is Tafel slope.

Charge transport in the electrode and electrolyte is based on Ohm's law, described by:

$$
\nabla i_{1}=Q_{1}
$$




$$
\begin{aligned}
& i_{1}=-\sigma_{1} \nabla \varphi_{1} \\
& \nabla i_{\mathrm{s}}=Q_{\mathrm{s}} \\
& i_{\mathrm{s}}=-\sigma_{\mathrm{s}} \nabla \varphi_{\mathrm{s}}
\end{aligned}
$$

In eqn. (11), $i_{1}$ is the current density, $Q_{1}$ is a source term, $\sigma$ is the conductivity and $\varphi_{1}$ is the potential in electrolyte. In eqn, (12), $i_{s}$ the current density $Q_{s}$ is a source term, $\sigma_{s}$ is the conductivity and $\varphi_{\mathrm{s}}$ is the potential in electrode.

The concentrations of hydrogen and oxygen at the electrode-membrane interface can be determined from Henry's law equation of the forms expressed in the following two equations $[17,18]$ :

$$
\begin{aligned}
& C_{\mathrm{H}_{2}}=\frac{x_{\mathrm{H}} p_{\mathrm{H}}}{K_{\mathrm{H}}} \\
& C_{\mathrm{O}_{2}}=\frac{x_{\mathrm{O}} p_{\mathrm{O}}}{K_{\mathrm{O}}}
\end{aligned}
$$

where, $x_{H}$ and $x_{O}$ are mass fraction of hydrogen and oxygen respectively. $K_{H}$ and $K_{O}$ are Henry's constants and $p_{\mathrm{H}}, p_{\mathrm{O}}$ pressure for hydrogen and oxygen in fuel cell channel.

\section{Brinkman equations (anode)}

In porous media of the catalyst and diffusion layers, the Navier-Stokes equation is changed into the Brinkman equations and chemical species transport in ideal gas mixtures is described by the Maxwell-Stefan equation $[17,18]$.

$$
\begin{aligned}
& \frac{\rho}{\varepsilon_{\mathrm{p}}}\left(\vec{u}_{a} \nabla\right) \vec{u}_{\mathrm{a}} \frac{1}{\varepsilon_{\mathrm{p}}}=\nabla\left[-p_{\mathrm{a}} I_{\mathrm{i}, \mathrm{j}}+\mu \frac{1}{\varepsilon_{\mathrm{p}}}\left(\nabla \vec{u}_{\mathrm{a}}+\left(\nabla \vec{u}_{\mathrm{a}}\right)^{T}\right)-\frac{2}{3} \mu \frac{1}{\varepsilon_{\mathrm{p}}}\left(\nabla \vec{u}_{\mathrm{a}}\right) I_{\mathrm{i}, \mathrm{j}}\right]-\left(\mu \kappa^{-1}+\beta_{\mathrm{f}}\left|\vec{u}_{\mathrm{a}}\right|+\frac{Q_{\mathrm{m}}}{\varepsilon_{\mathrm{p}}^{2}}\right) \vec{u}_{\mathrm{a}}+F \\
& \nabla\left(\rho \vec{u}_{\mathrm{a}}\right)=Q_{\mathrm{m}}
\end{aligned}
$$

Brinkman equations (cathode)

$$
\begin{aligned}
& \frac{\rho}{\varepsilon_{\mathrm{p}}}\left(\vec{u}_{\mathrm{c}} \nabla\right) \vec{u}_{\mathrm{c}} \frac{1}{\varepsilon_{\mathrm{p}}}=\nabla\left[-p_{\mathrm{c}} I_{\mathrm{i}, \mathrm{j}}+\mu \frac{1}{\varepsilon_{\mathrm{p}}}\left(\nabla \vec{u}_{\mathrm{c}}+\left(\nabla \vec{u}_{\mathrm{c}}\right)^{T}\right)-\frac{2}{3} \mu \frac{1}{\varepsilon_{\mathrm{p}}}\left(\nabla \vec{u}_{\mathrm{c}}\right) I_{\mathrm{i}, \mathrm{j}}\right]-\left(\mu \kappa^{-1}+\beta_{\mathrm{f}}\left|\vec{u}_{\mathrm{c}}\right|+\frac{Q_{\mathrm{m}}}{\varepsilon_{\mathrm{p}}^{2}}\right) \vec{u}_{\mathrm{c}}+F \\
& \nabla\left(\rho \vec{u}_{\mathrm{c}}\right)=Q_{\mathrm{m}}
\end{aligned}
$$

where $\varepsilon_{\mathrm{p}}$ is gas diffusion layer porosity, $p_{\mathrm{c}}$ and $p_{\mathrm{a}}$ are pressure at cathode and anode, $u_{\mathrm{c}}$ and $u_{\mathrm{a}}$ is inlet velocity vector at cathode and anode respectively, $\kappa$ is permeability of porous media, $l_{i, j}$ is identity tensor, $\rho$ is density and $Q_{m}$ is mass source.

\section{Boundary condition}

$$
\begin{aligned}
& \text { Wall -no slip } \\
& \vec{u}_{\mathrm{a}}=\vec{u}_{\mathrm{c}}=0
\end{aligned}
$$

Cathode inlet - pressure inflow

$$
n^{T}\left[-p_{\mathrm{c} i, j}+\mu \frac{1}{\varepsilon_{\mathrm{p}}}\left(\nabla \vec{u}_{\mathrm{c}}+\left(\nabla \vec{u}_{\mathrm{c}}\right)^{T}\right)-\frac{2}{3} \mu \frac{1}{\varepsilon_{\mathrm{p}}}\left(\nabla \vec{u}_{\mathrm{c}}\right) I_{\mathrm{i}, \mathrm{j}}\right] n=-p_{0}
$$

Anode inlet - pressure inflow

$$
n^{T}\left[-p_{\mathrm{a}} I_{\mathrm{i}, \mathrm{j}}+\mu \frac{1}{\varepsilon_{\mathrm{p}}}\left(\nabla \vec{u}_{\mathrm{a}}+\left(\nabla \vec{u}_{\mathrm{a}}\right)^{T}\right)-\frac{2}{3} \mu \frac{1}{\varepsilon_{\mathrm{p}}}\left(\nabla \vec{u}_{\mathrm{a}}\right) I_{\mathrm{i}, \mathrm{j}}\right] n=-p_{0}
$$

where $p_{0}$ is inlet pressure. 


\section{Transport of concentrated species for anode and cathode}

The equation is given by

$$
\nabla j_{\mathrm{i}}+\rho(\vec{u} \nabla) \omega_{\mathrm{i}}=R_{\mathrm{i}}
$$

where $j_{i}$ is flux density, $u$ is velocity vector, $\rho$ is density and $\omega_{i}$ is mass fraction.

Anode and cathode outlet boundary condition: pressure $\left(p_{0}=0\right)$.

\section{Numerical methods}

A three-dimensional computational domain of a single unit of solid oxide fuel cell (SOFC) is shown in Figure 1.

In our optimization, various cathode to anode electrode thickness, rib width and channel width are considered for analysis. To study the effect of all ratios individually, other flow channel parameters were considered constant. Rib width is considered equal on both sides of channel. In our analysis, three different ratios of cathode to anode electrode thickness $(1,1.5,2)$, and channel to rib width $(0.5,0.75,1)$ are considered to observe fuel cell performance at flow rates of 0.0002 and $0.0003 \mathrm{~mm}^{3} / \mathrm{s}$. At the fixed flow rate, rib width is analysed for higher values of $1 \mathrm{~mm}, 1.25 \mathrm{~mm}$ and $1.5 \mathrm{~mm}$. Structural hexahedral elements are used for meshing of computational flow domain. Mesh distribution across computational domain is shown in Figure 2.

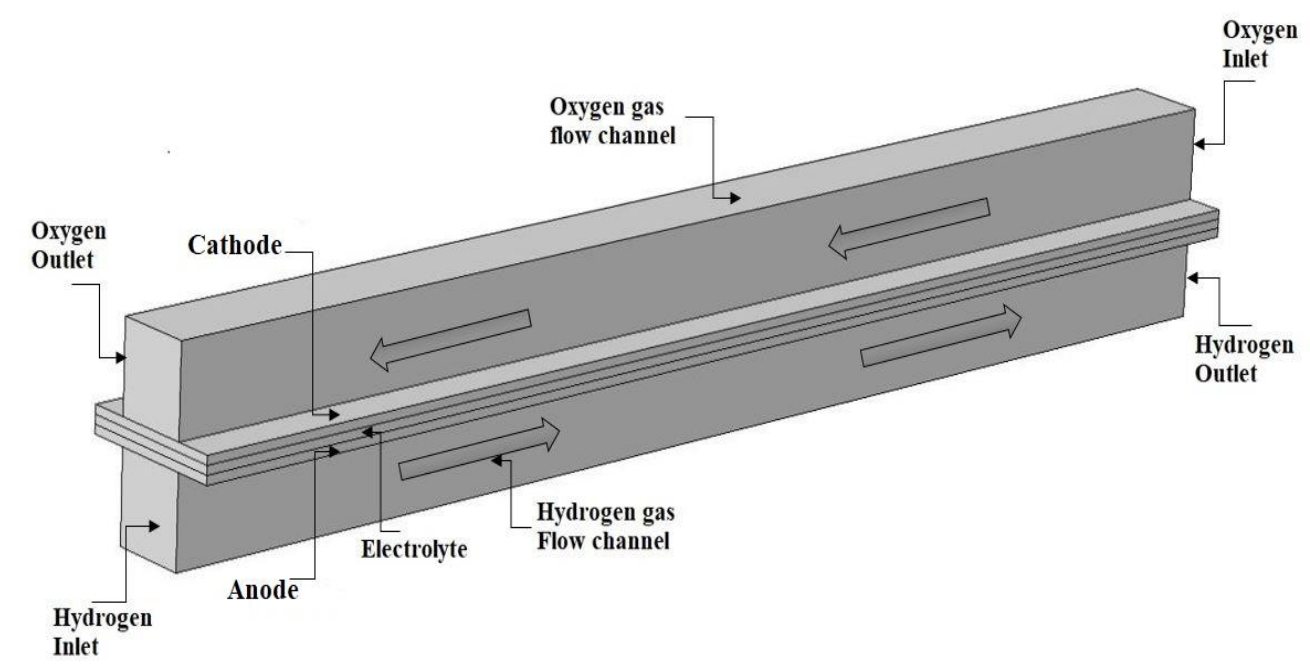

Figure 1. Schematic of SOFC

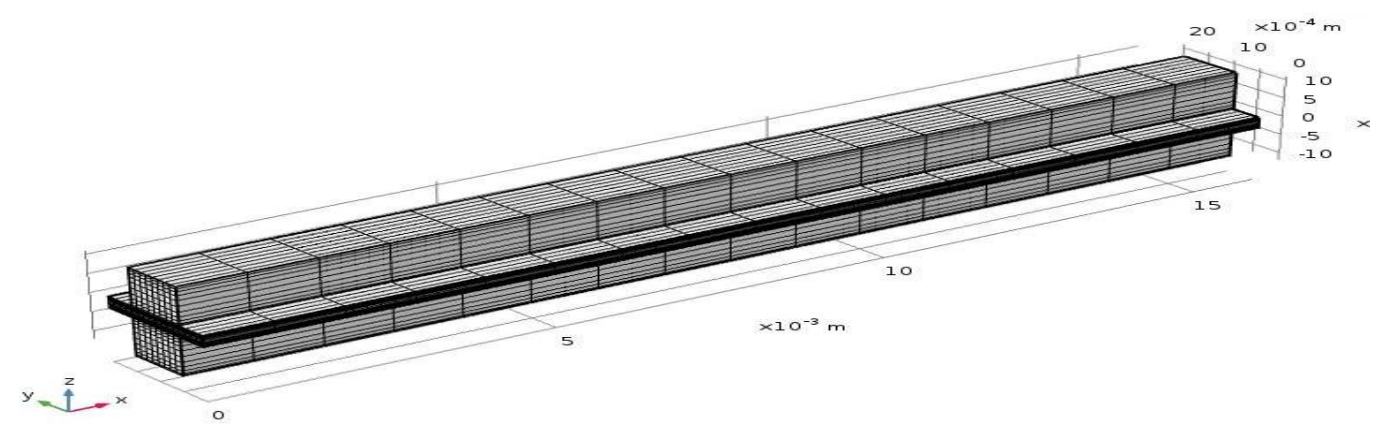

Figure 2. Mesh distribution across computational domain of SOFC

Our computational domain consists of 7424 hexahedral mesh elements, 3456 boundary elements and 572 edge elements. Average skewness quality of our mesh elements is 1 . Maximum element size of $1.6 \mathrm{~mm}$ and minimum element size of $0.288 \mathrm{~mm}$ is used for meshing. Mesh elements of our computational domain are adaptive with respect to various cathode to anode thickness ratios and channel width to channel depth ratios. 
Figures 3(a), 3(b) and 3(c) show mesh distribution across cross section of three different cathode to anode thickness ratios $(1,1.5,2)$ configurations.

a

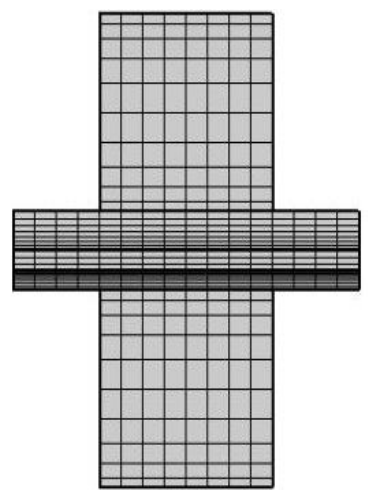

b

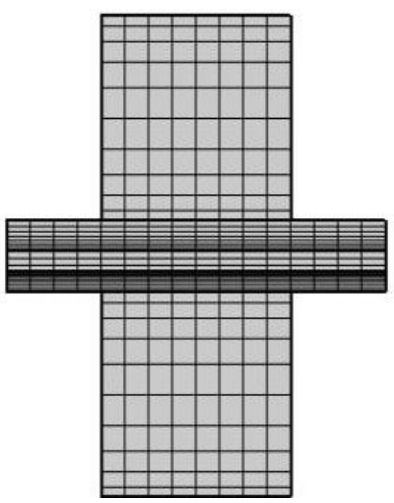

C

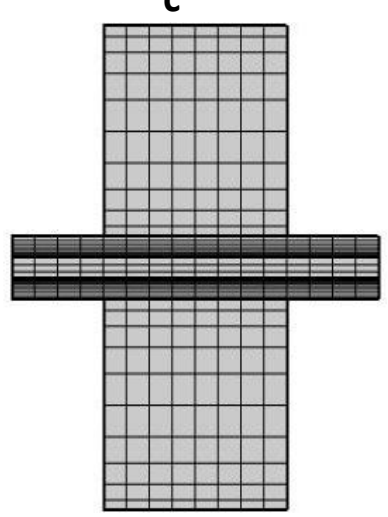

Figure 3. Mesh distribution across cross section of SOFC configurations with cathode to anode thickness ratio: (a) 1; (b) 1.5; (c) 2

Grid independence test is done for 6800, 7424, 8756 and 10512 number of mesh elements. For various mesh sizes, the fuel cell performance variance is negligible as shown in Table 1. A mathematical model is developed to analyse our computational domain in Comsol software version 5.3a on performance of solid oxide fuel cell, fluid dynamics, species transport and current distribution.

Table 1. Grid independence test for current density at $101325 \mathrm{~Pa}$ pressure and $1073 \mathrm{~K}$ temperature

\begin{tabular}{cccc}
\hline \multirow{2}{*}{$\begin{array}{c}\text { Number of mesh } \\
\text { elements }\end{array}$} & \multicolumn{3}{c}{ Cathode to anode thickness ratio } \\
\cline { 2 - 4 } & \multicolumn{3}{c}{1.5} \\
\hline 6800 & 4848.0 & Current density, A m ${ }^{-2}$ & 5232.8 \\
\hline 7424 & 4848.3 & 5109.8 & 5234.1 \\
\hline 8656 & 4847.7 & 5110.6 & 5233.7 \\
\hline 10512 & 4847.1 & 5110.3 & 5233.8 \\
\hline
\end{tabular}

\section{Results}

\section{Cathode to anode thickness ratio}

Solid oxide fuel cell performance is studied under various operating conditions and parameters. Figure 4 shows the current density variation for different SOFC configurations with respect to cathode to anode thickness ratio. It is observed from Figure 4 that as the cathode to anode thickness ratio increased from 1 to 2 , the current density increases by $8.5 \%$, from 4800 to $5250 \mathrm{~A} / \mathrm{m}^{2}$. Increasing the cathode thickness gives rise to several outcomes. The reactive active sites (RAS) for the evolution of oxygen ions increases with increasing the cathode thickness. The cathode thickness should be optimized in such a way that there is sufficient RAS for the cathode reaction, but the reactant gas should be able to diffuse through to the reaction sites. Increasing the cathode thickness also increases the ohmic resistance across the cell. Thus, optimizing of the cathode thickness is very critical to SOFC performance. The generation of oxygen ions on the cathode is the driving force for the anode reaction as per equation 2. Figure 4 indicates that increasing the cathode to anode thickness ratio from 1 to 1.5 causes an increase in the performance of the SOFC, while increasing the cathode to anode thickness ratio from 1.5 to 2 causes a very limited increase in the performance of the SOFC. Figure 5 shows that as cathode to anode thickness ratio increased from 1 to 2 , the average cell power increases by $13.3 \%$, from 1280 to $1450 \mathrm{~W} / \mathrm{m}^{2}$. However, it is seen that the increase in power density when the thickness ratio is increased from 1.5 to 2 is lesser than when the thickness ratio is increased from 1 to 
1.5. This indicates that increasing the thickness ratio beyond a certain value does not improve SOFC performance. It is highly possible that with increasing cathode thickness, RAS increases, increasing the generation of oxygen ions which drive the power density of SOFC. However, the increasing thickness of the cathode film increases the ohmic resistance of the cell, causing power density to decrease. The optimum value of cathode thickness needs to be identified so that the maximum power density of the SOFC can be obtained. Sun et al. [2] postulated that for the optimum performance of SOFC, the cathode to anode area should be close to 1 . Our simulation results indicate that the cathode/anode thickness of 1.5 would be ideal for the optimum performance of SOFC. Figures 6 and 7 show the fuel utilization and hydrogen mole fraction variation across SOFC channel length. It is observed from these figures that as cathode to anode thickness ratio increases, reactive area increases, and more hydrogen fuel is consumed per unit length of SOFC channel. Figures 6 and 7 show that increasing cathode to anode thickness ratio from 1 to 2 leads to $3 \%$ increment in hydrogen fuel consumption. Figure 8 shows oxygen mole fraction along the SOFC channel length. It is observed that with increase in cathode to anode thickness ratio, fuel oxidation increases, and more oxygen is consumed with increase in the reaction rate. Sun et al. [2] have postulated that cathode to anode thickness ratio should be close to 1 for efficient performance of the fuel cell. Although in our simulation we further increased cathode to anode thickness ratio from 1 to 2, which increases cathode reaction area, more oxygen ion formation for driving force to anode reaction as defined earlier and leads to increase in more current and power density.

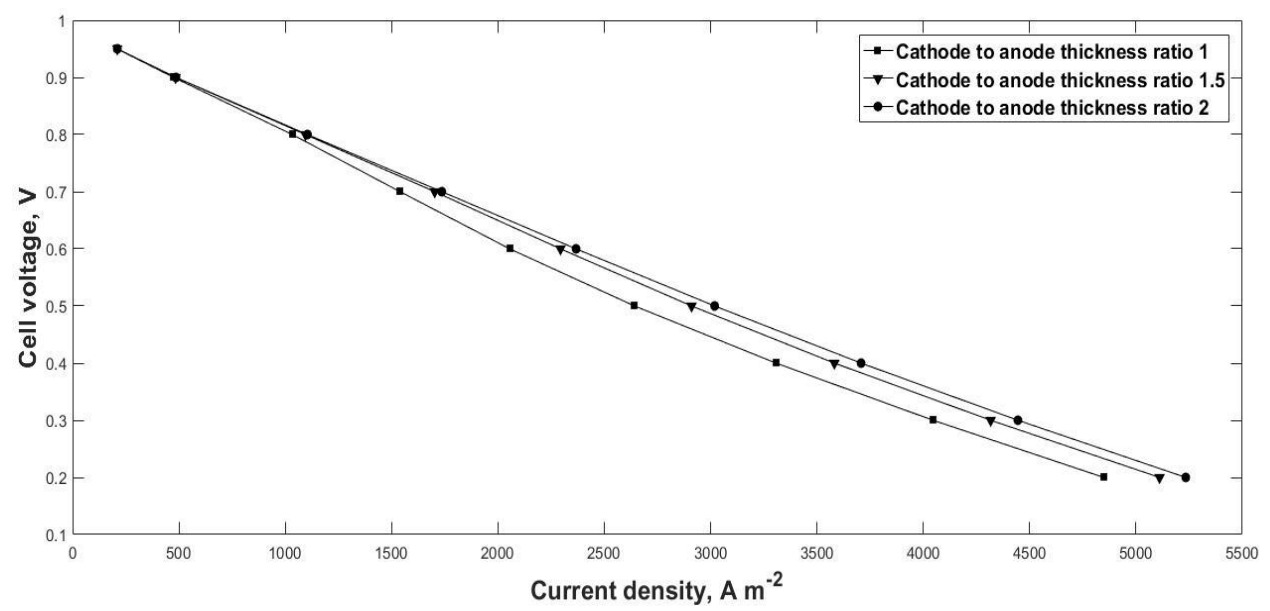

Figure 4. Polarization curve of SOFC for various cathode to anode thickness ratios

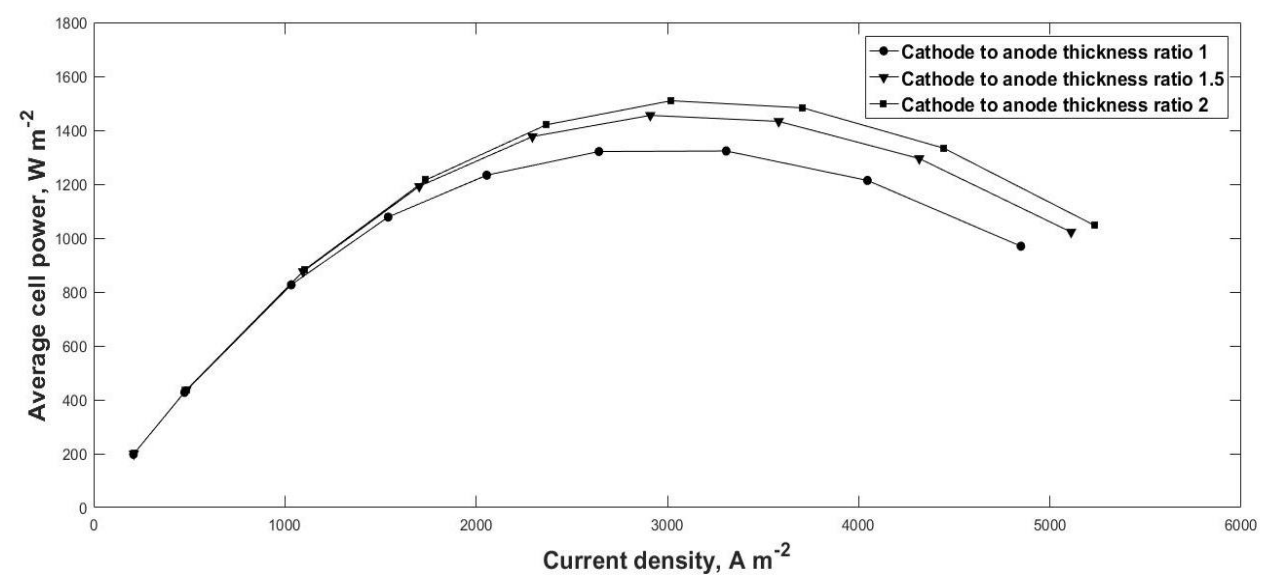

Figure 5. Cell power and current density variation of SOFC for various cathode to anode thickness ratios 


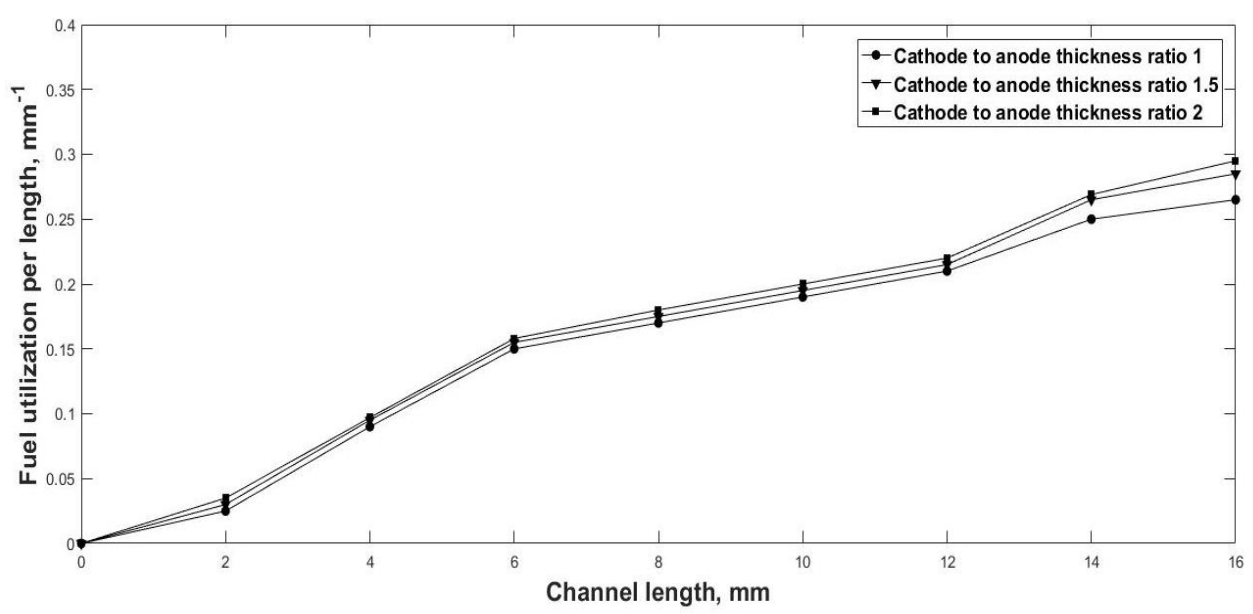

Figure 6. Fuel utilization per channel length of SOFC for various cathode to anode thickness ratios

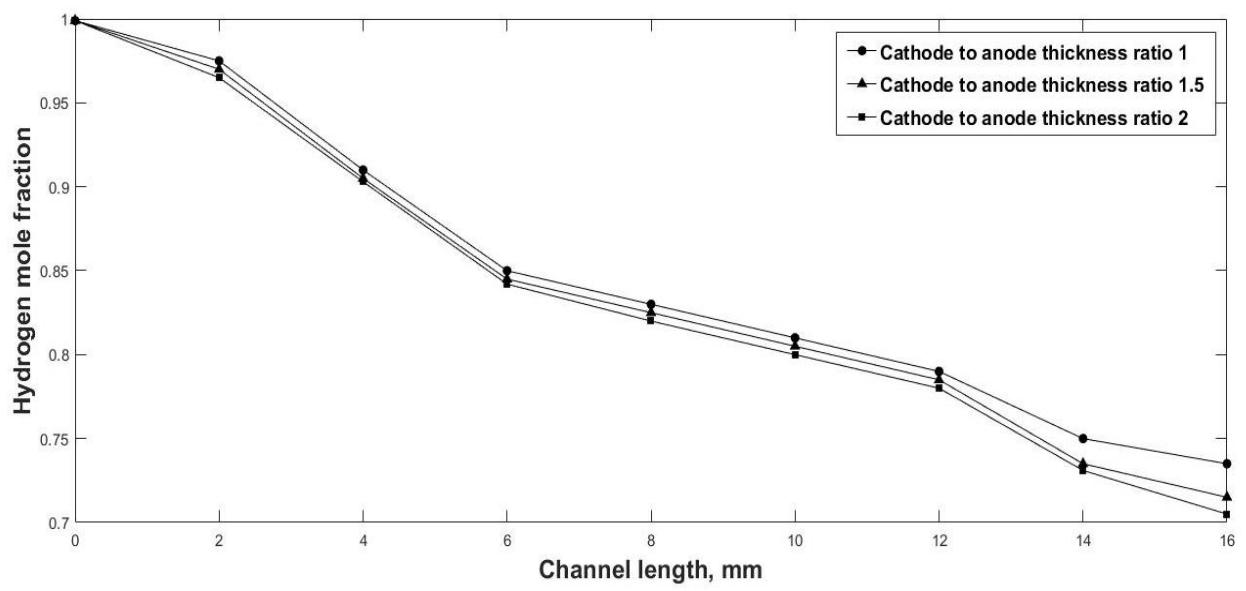

Figure 7. Hydrogen mole fraction of SOFC for various cathode to anode thickness ratios

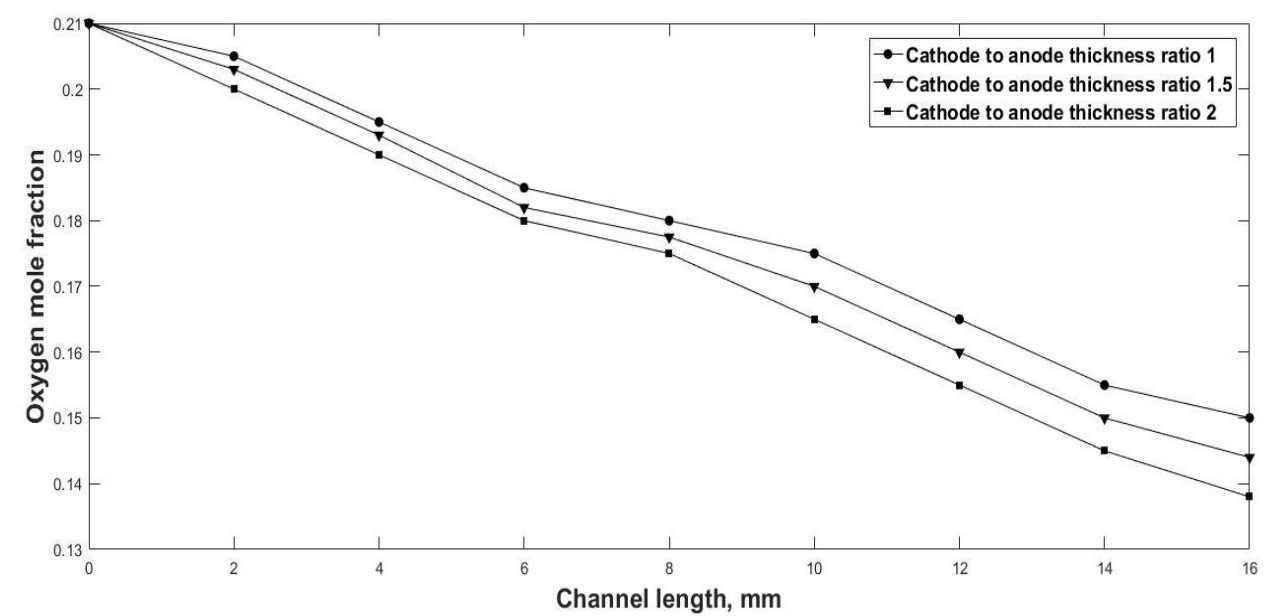

Figure 8. Oxygen mole fraction of SOFC for various cathode to anode thickness ratios

\section{Rib width}

The SOFC performance with various channel and rib widths is also studied. The ribs which separate and define flow channels make a direct contact with electrodes. To optimize the performance, there must be a trade-off between the rib and channel sizes. On one hand, wider ribs and ribs covering bigger fraction of the cell area may reduce the interface resistance to current flow by increasing the electrode interconnect contact area with electrodes and reducing the current path through the electrode material [19]. Such ribs will give better conduction of the electrical current and reduce ohmic losses. However, chemical species do not diffuse very well under wide ribs. 
Narrow ribs are required to facilitate more uniform distribution of the reactive gases across the area of the electrode surface and promote electrochemical performance. It is very important to understand this trade-off between rib dimensions and performance of the SOFC. Figure 9 shows polarization curve of SOFC for various rib widths. It is observed from this figure that as rib width of SOFC increases from 1-to $1.25 \mathrm{~mm}$, the current density decreases by $10.11 \%$, from 4450 to $4000 \mathrm{~A} / \mathrm{m}^{2}$. Further increasing of rib width to $1.5 \mathrm{~mm}$ leads to further reduction of current density by $10 \%$, from 4000 to $3600 \mathrm{~A} / \mathrm{m}^{2}$. Increase of rib width will also lead to larger contact area resistance which will lead to decrease in the fuel cell performance. When the rib width is higher, due to more contact resistance, gas concentration is not uniform across fuel cell and lower compared to the narrow rib width. Hence, lower rib width is better than higher rib width configuration. Figure 10 shows the variation of cell power and current density for different rib widths. It shows that as the rib width increases from 1 to $1.5 \mathrm{~mm}$, peak cell power decreases by $13.27 \%$, from 1311 to 1137 $\mathrm{W} / \mathrm{m}^{2}$. Figures 11 and 12 show hydrogen fuel consumption across channel length for various rib widths. These figures show that with increase of rib width from 1 to $1.5 \mathrm{~mm}$, hydrogen fuel consumption is decreased from 18 to $6 \%$. Figure 13 shows oxygen mole fraction for various rib widths along flow channel length. It shows that with an increase in rib width, oxygen consumption is reduced from 23.80 to $9.5 \%$.

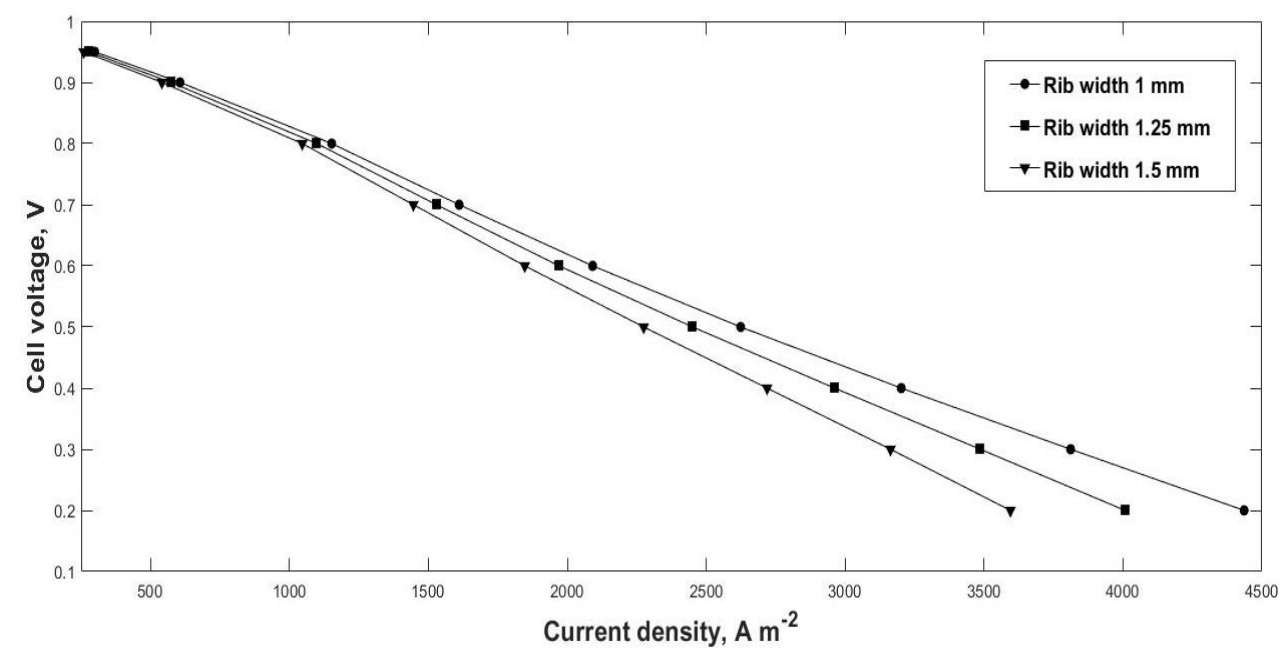

Figure 9. Polarization curve of SOFC for various rib widths

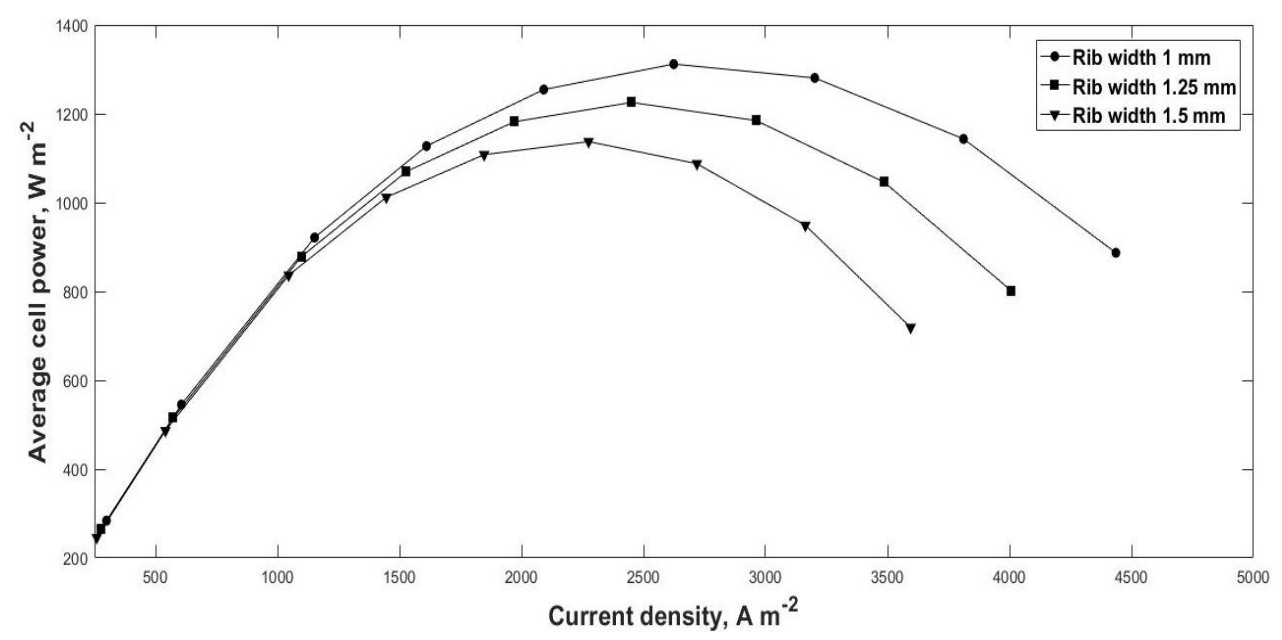

Figure 10. Cell power and current density variation of SOFC for various rib widths 


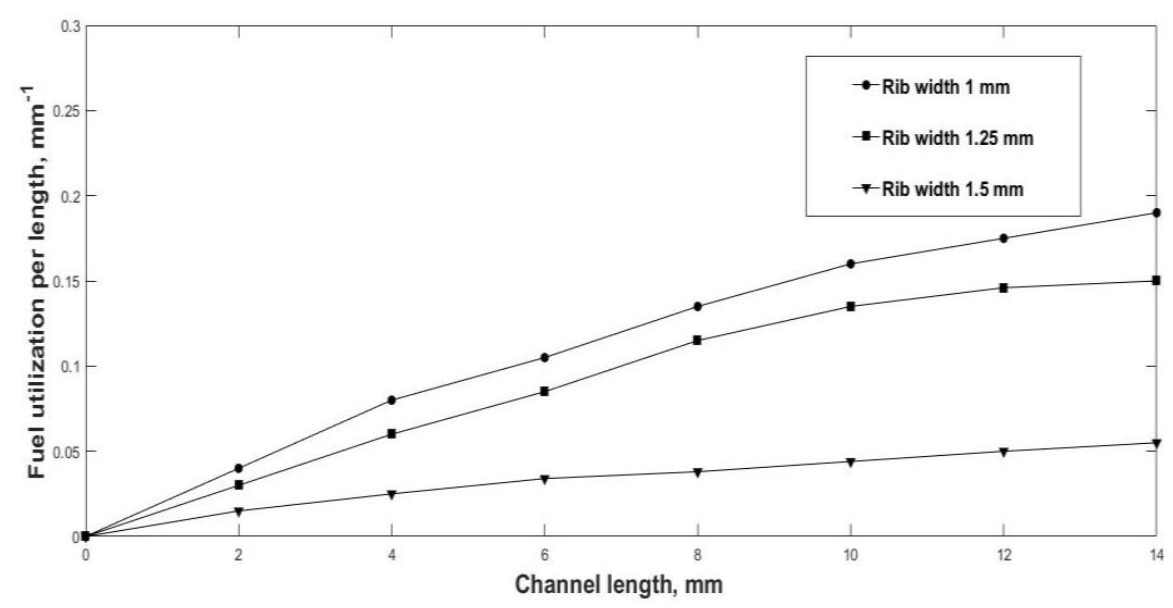

Figure 11. Fuel utilization per channel length of SOFC for various rib widths

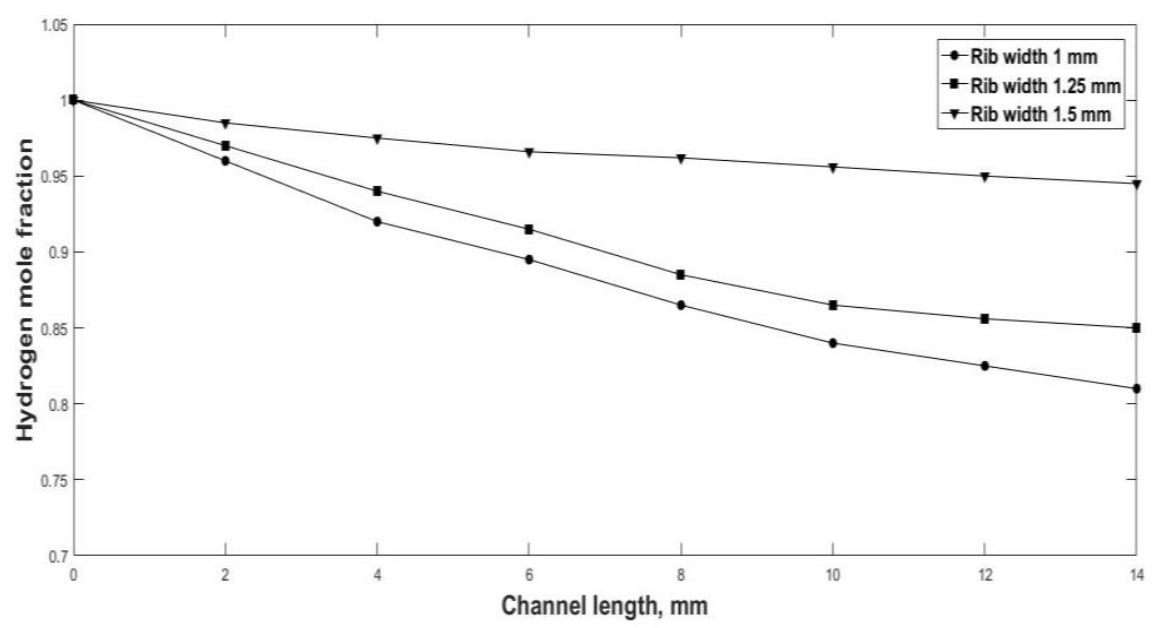

Figure 12. Hydrogen mole fraction of SOFC for various rib widths

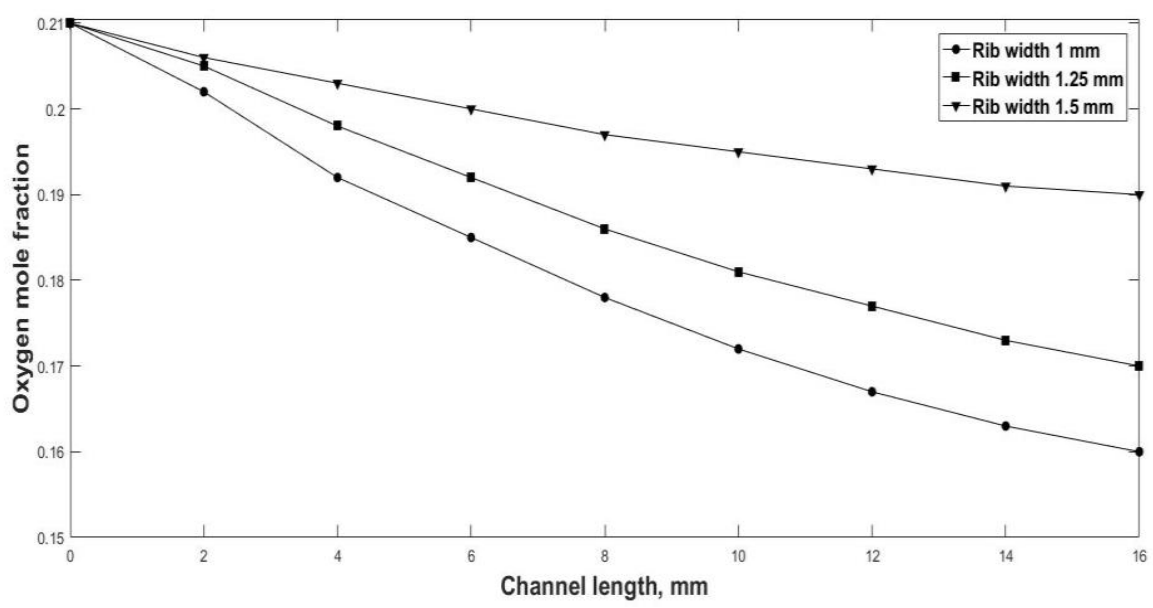

Figure 13. Oxygen mole fraction of SOFC for various rib widths

Flow rate to rib width ratio

Solid oxide fuel cell performance decreases as rib width were increased from 1 to $1.5 \mathrm{~mm}$. For further analysis, smaller rib width $(0.5 \mathrm{~mm}, 0.75 \mathrm{~mm}, 1 \mathrm{~mm})$ is considered at 0.0002 and $0.003 \mathrm{~mm}^{3} / \mathrm{s}$ volumetric flow rates. Figure 14 shows the polarization curve for different flow rate to rib width ratios. It is observed from Figure 14 that as the rib width was decreased from 1 to $0.5 \mathrm{~mm}$, the current density increased. Also, the current density increased with the increase of the volumetric flow rate for the same rib width. Lower rib widths with higher flow rates seem to give the maximum 
current density. Similarly, Figure 15 shows the average cell power along with current density variation for various flow rate to rib width ratios. For higher flow rate to rib width ratio, the current density, as well as average cell power increased. With increase of the flow rate, more hydrogen fuel is consumed during reaction, what leads to higher reaction rate and increase of the current density.

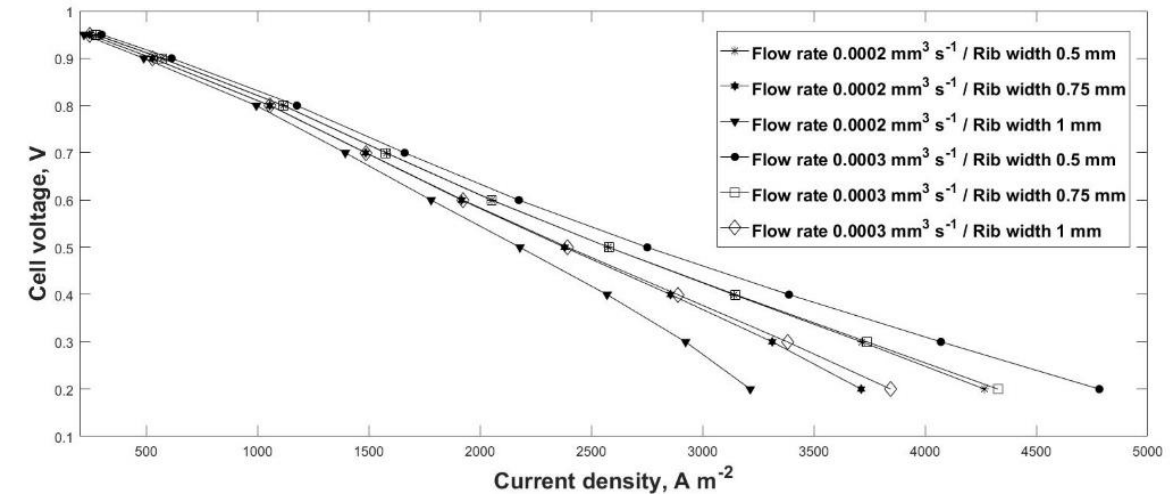

Figure 14. Polarization curve of SOFC for various flow rate to rib width ratios

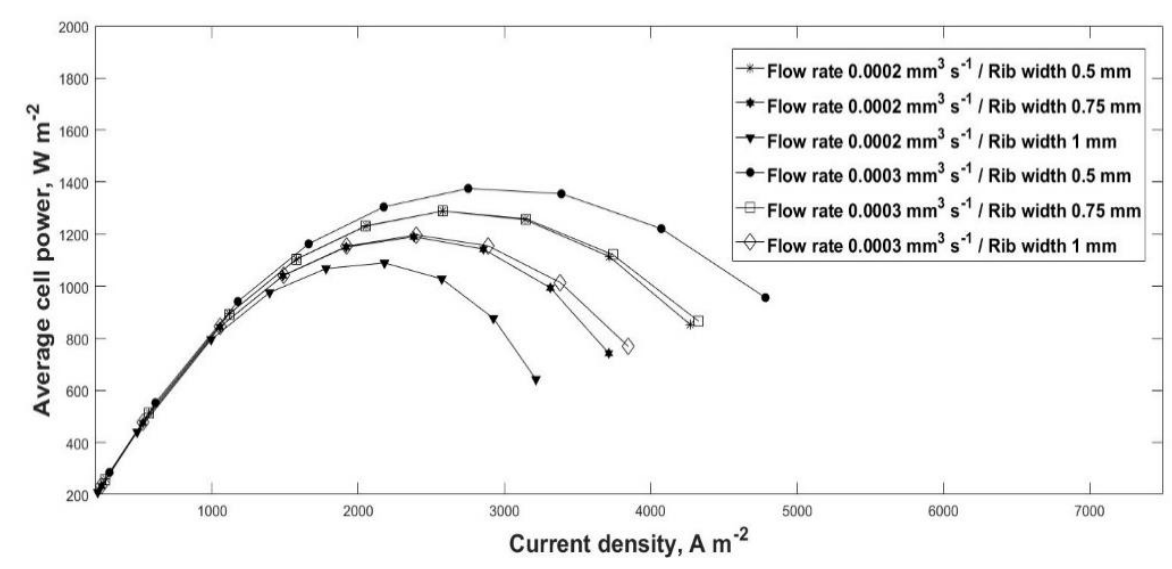

Figure 15. Cell power and current density variation of SOFC for various flow rate to rib width ratios

Flow rate to channel width ratio

SOFC fuel cell performance is studied for various flow rate to channel width ratios, and polarization curves are presented in Figure 16. From Figure 16 it is observed that as the channel width was increased from 0.5 to $1 \mathrm{~mm}$, the current density increased. Increasing the volumetric flow rate is also seen to increase the current density.

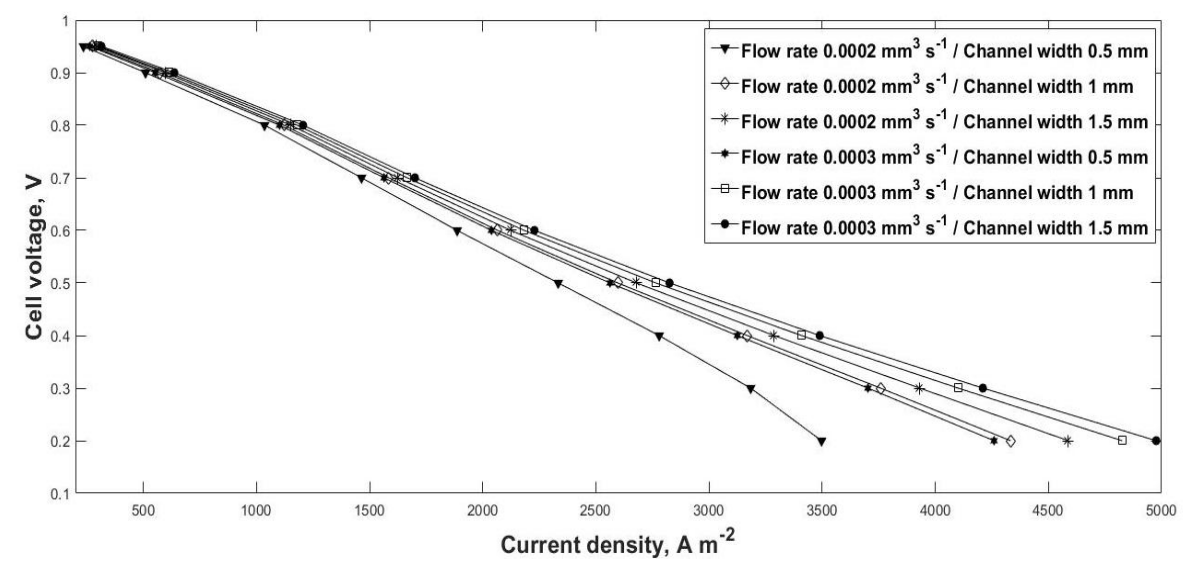

Figure 16. Polarization curve of SOFC for various flow rate to channel width ratios 
Further increase in channel width from 1 to $1.5 \mathrm{~mm}$ also increased the fuel cell performance but with less increment in current density values. Similarly, Figure 17 shows average cell power along with current density variation for various flow rate to channel width ratios. For higher flow rate to channel width ratio, current density, as well as average cell power increased. With an increase in channel width, the reaction area increases what leads to transport of more fuel for reaction driving the reaction rate.

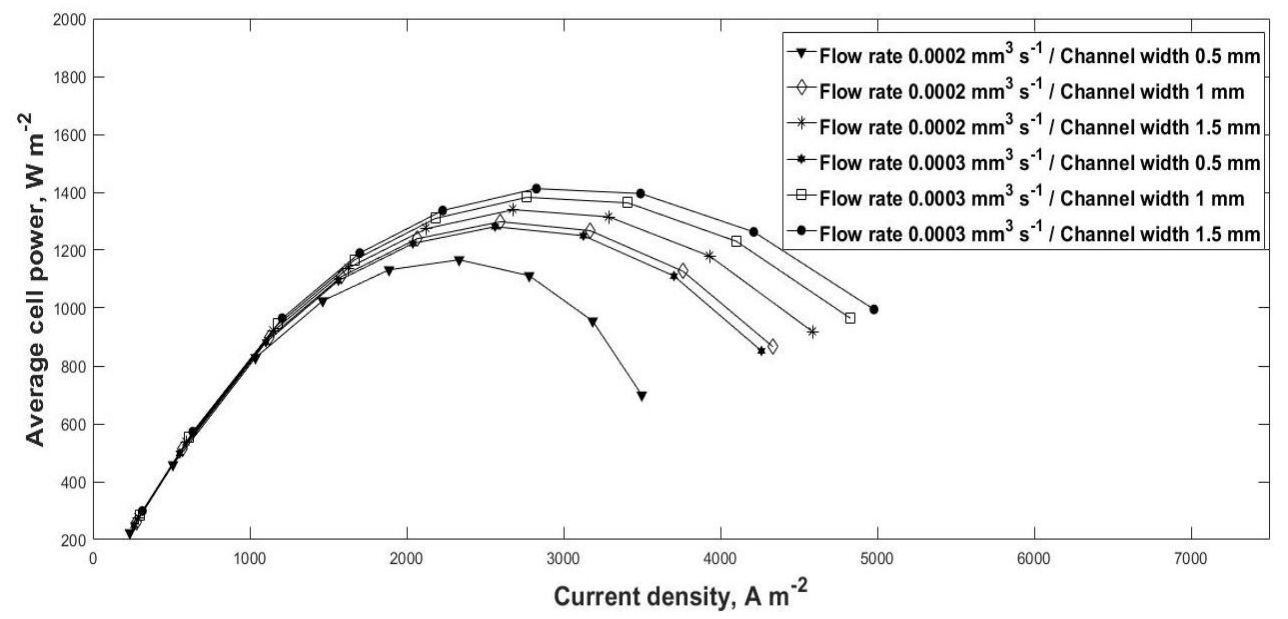

Figure 17. Cell power and current density variation of SOFC for various flow rate to channel width ratios

Figure 18 shows the comparison between simulation results and experimental data. Sun et al. [2] studied experimental modelling of single chamber solid oxide fuel cell at various temperatures and electrode particles. In Figure 18, simulation results are compared with the experimental polarization graph at $873 \mathrm{~K}$ temperature, showing well agreement.

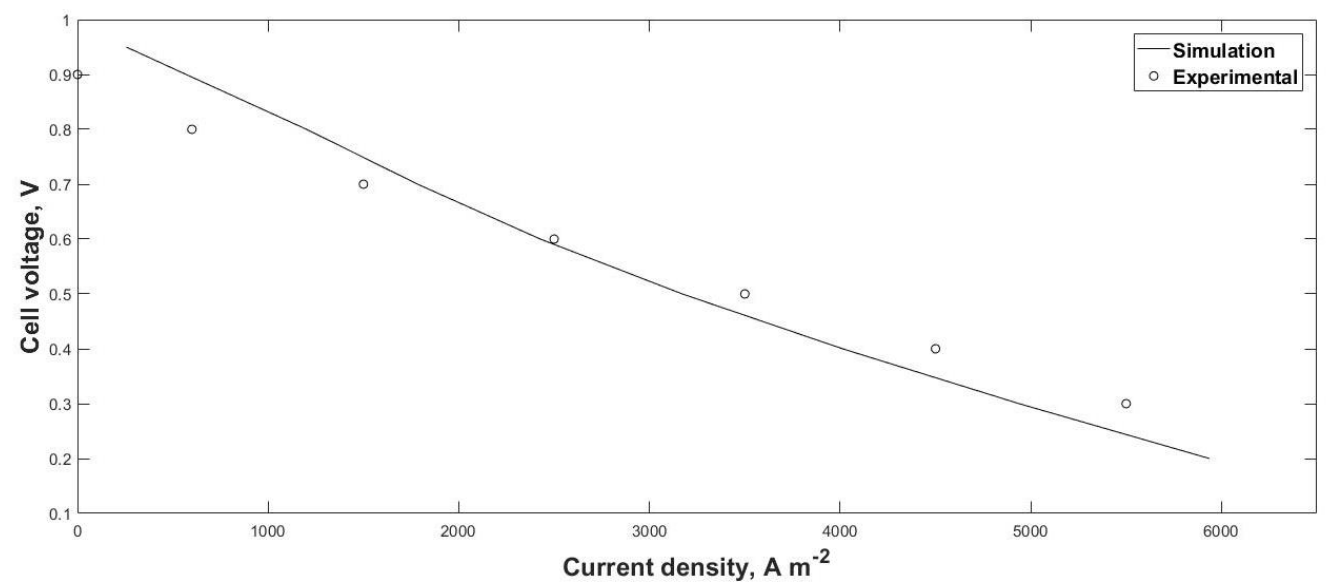

Figure 18. Comparison of simulation with experimental data [2] at $873 \mathrm{~K}$ temperature

\section{Conclusion}

A 3D mathematical model is developed to study the effect of various geometrical parameters such as cathode to anode thickness ratio, rib width, and channel width at different flow rates, on the performance of 3-dimensional model of solid oxide fuel cell (SOFC). Simulation results show that performance of SOFC fuel cell is increased at higher cathode to anode thickness. From simulation results, it is also observed that as the rib width increases, due to increase of the contact area resistance, the fuel cell performance and average cell power decrease. However, with increase in 
channel width, the current density is increased due to increase of the reaction area and consequently, the average cell power is also increased. Simulation results indicate that the cathode supported SOFC show better performance as the cathode to anode thickness ratio was increased. It is also observed that flow rate plays major role in the fuel cell performance. It is seen that with increase in the volumetric flow rate at various rib and channel widths, the performance of SOFC fuel cell increases. Higher cathode to anode thickness ratio, smaller rib widths, larger channel widths and increasing volumetric flow rate are found to increase the performance of the fuel cell. Model results are compared with experimental data taken from the literature and found to compare well.

\section{List of parameters $[17,18]$}

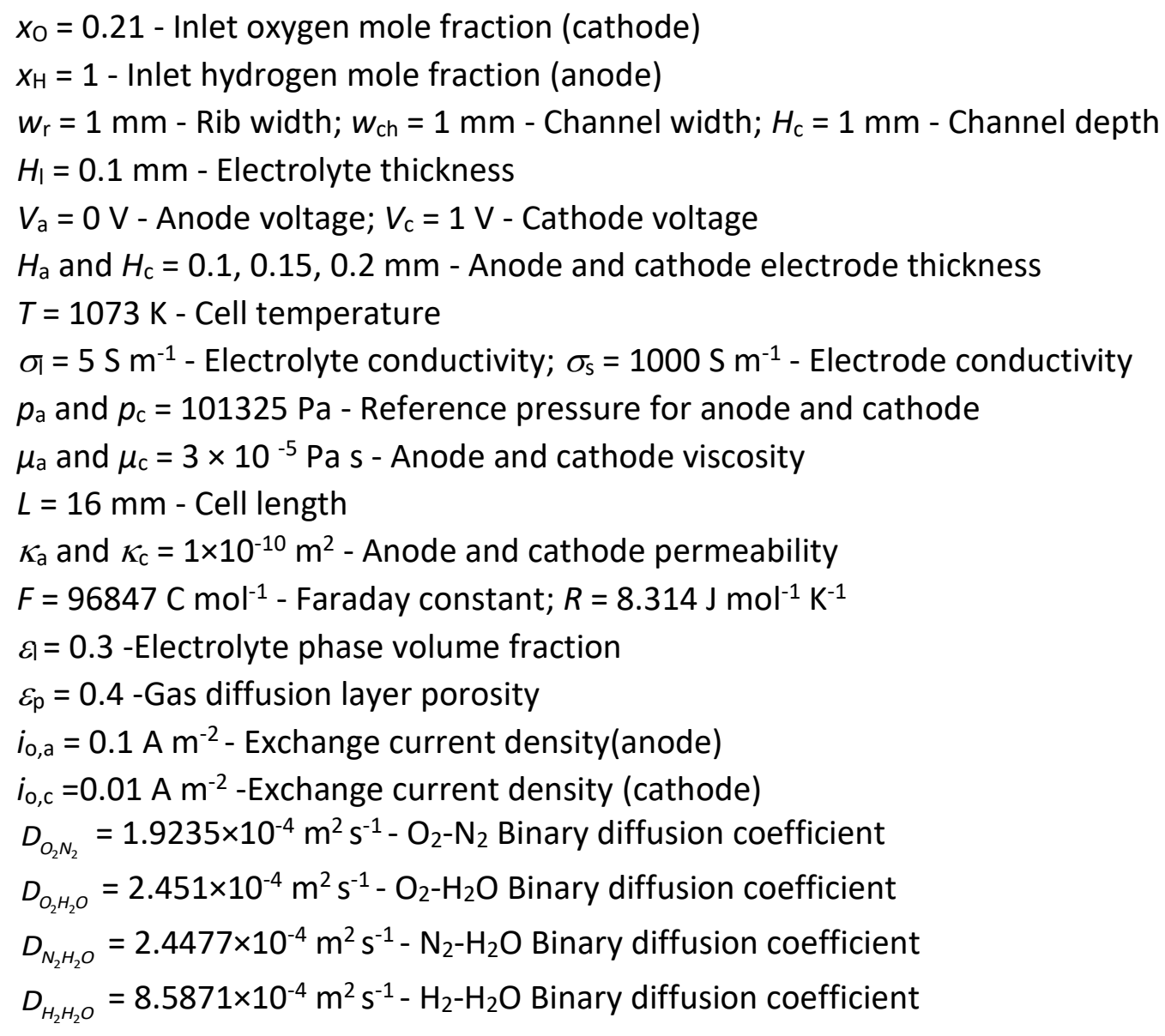

\section{Data availability statement}

Some or all data, models, or code that support the findings of this study are available from the corresponding author upon reasonable request.

Acknowledgement: The authors would like to acknowledge BITS Pilani, Hyderabad and Council for Scientific and Industrial Research, CSIR Grant No: [22/0784/19/EMR II] which helped us in publishing this article.

\section{References}

[1] H. Yakabe, T. Ogiwara, M. Hishinuma, I. Yasuda, Journal of Power Sources 102(1-2) (2001) 144154. https://doi.org/10.1016/S0378-7753(01)00792-3

[2] L. P. Sun, M. Rieu, J. P. Viricelle, C. Pijolat, H. Zhao, International Journal of Hydrogen Energy 39(2) (2014) 1014-1022. https://doi.org/10.1016/i.ijhydene.2013.10.117

[3] P. Chinda, Energy Procedia 34 (2013) 243-261. https://doi.org/10.1016/i.egypro.2013.06.753 
[4] S. Su, X. Gao, Q. Zhang, W. Kong, D. Chen, International Journal of Electrochemical Science 10 (2015) 2487-2503.

[5] V. Zaccaria, D. Tucker, A. Traverso, Journal of Power Sources 327 (2016) 736-742. https://doi.org/10.1016/i.jpowsour.2016.01.027

[6] V. Zaccaria, D. Tucker, A. Traverso, Journal of Power Sources 311 (2016) 175-181. https://doi.org/10.1016/i.jpowsour.2016.02.040

[7] A. Cuneo, V. Zaccaria, D. Tucker, A. Traverso, Energy 141 (2017) 2277-2287. https://doi.org/10.1016/j.energy.2017.12.002

[8] G. Giacoppo, O. Barbera, N. Briguglio, F. Cipitì, M. Ferraro, G. Brunaccini, E. Erdle, V. Antonucci, International Journal of Hydrogen Energy 42(46) (2017) 28022-28033. https://doi.org/10.1016 Li.ijhydene.2017.09.063

[9] M. Z. Khan, R.-H. Song, A. Hussain, S.-B. Lee, T.-H. Lim, J.-E. Hong, Journal of the European Ceramic Society 40(4) (2020) 1407-1417. https://doi.org/10.1016/j.jeurceramsoc.2019.11.017

[10] M. Z. Khan, M. T. Mehran, R.-H. Song, J.-W. Lee, S.-B. Lee, T.-H. Lim, Journal of Power Sources 391 (2018) 94-105. https://doi.org/10.1016/i.jpowsour.2018.04.080

[11] Q. Shen, L. Sun, B. Wang, International Journal of Electrochemical Science 14 (2019) 1698-1712. https://doi.org/10.20964/2019.02.11

[12] M. Bianco, J. P. Ouweltjes, J. Van herle, International Journal of Hydrogen Energy 44(59) (2019) 31406-31422. https://doi.org/10.1016/i.ijhydene.2019.09.218.

[13] S. Dwivedi, International Journal of Hydrogen Energy 45(44) (2020) 23988-24013. https://doi. org/10.1016/j.ijhydene.2019.11.234

[14] M. Zhou, X. Wang, Y. Zhang, Q. Qiu, M. Liu, J. Liu, Solid State lonics 343 (2019) 115127. https://doi.org/10.1016/i.ssi.2019.115127

[15] G. Min, Y. J. Park, J. Hong, Energy Conversion and Management 209 (2020) 112614. https://doi.org/10.1016/i.enconman.2020.112614

[16] Y. Wang, W. Jiang, M. Song, Y. Luo, S. T. -Tu, Journal of Power Sources 450 (2020) 227663. https://doi.org/10.1016/j.jpowsour.2019.227663

[17] J. Hussain, R. Ali, M. N. Akhtar, M. H. Jaffery, I. Shakir, R. Raza, Current Applied Physics 20(5) (2020) 660-672. https://doi.org/10.1016/i.cap.2020.02.018

[18] Batteries \& Fuel Cells Module, User's Guide, COMSOL Multiphysics Help, 2012.

[19] Z. Lin, C. Song, S. Liu, Journal of Power Sources 183(1) (2008) 214-225. https://doi.org/10.1016 Li.jpowsour.2008.04.054

(C)2021 by the authors; licensee IAPC, Zagreb, Croatia. This article is an open-access article distributed under the terms and conditions of the Creative Commons Attribution license (https://creativecommons.org/licenses/by/4.0/) 